\title{
Inspeção no palacio de la luz - Montevideo: uma visão de durabilidade
}

\author{
M. H. F. Medeiros ${ }^{1}$, D. E. Giordano ${ }^{2}$, E. Pereira ${ }^{1}$, A. Vignolo ${ }^{3}$, R. Galeano ${ }^{3}$, P. Helene ${ }^{4}$ \\ ${ }^{1}$ Departamento de Construção Civil, Universidade Federal do Paraná (UFPR), Brasil. \\ ${ }^{2}$ Instituto Federal do Paraná (IFPR), Brasil. \\ ${ }^{3}$ Administración Nacional de Usinas y Transmisiones Eléctricas (UTE), Uruguai \\ ${ }^{4}$ Escola Politécnica, Universidade de São Paulo (USP), Brasil.
}

\section{Información del artículo DOI: \\ http://dx.doi.org/10.21041/ra.v2 \\ $\underline{i 2.30}$ \\ Artículo recibido el 15 de \\ Febrero de 2012, revisado bajo \\ las políticas de publicación de \\ la Revista ALCONPAT y \\ aceptado el 5 de Mayo de 2012. \\ Cualquier discusión, incluyendo \\ la réplica de los autores se \\ publicará en el primer número \\ del año 2013 siempre y cuando \\ la información se reciba antes \\ del cierre del tercer número del \\ año 2012}

(C) 2012 ALCONPAT Internacional

\section{Información Legal}

Revista ALCONPAT, Año 2, No. 2, Mayo Agosto 2012, es una publicación cuatrimestral Agosto 2012, es una publicación cuatrimestral
de la Asociación Latinoamericana de Control de Calidad, Patología y Recuperación de la Construcción, Internacional, A.C., Km. 6, antigua carretera a Progreso, Mérida Yucatán, C.P. 97310, Tel.5219997385893 ,

alconpat.int@gmail.com, Página Web: www.alconpat.org

Editor responsable: Dr. Pedro Castro Borges. Reserva de 2013-011717330300-203, 2013-011717330300-203, eISSN 2007-6835, ambos otorgados por el Instituto Nacional de Derecho de Autor. Responsable de la última actualización de este número, Unidad de Informática ALCONPAT, Ing. Elizabeth Sabido Maldonado, Km. 6, antigua carretera a Progreso, Mérida Yucatán, C.P. 97310, fecha de publicación: 30 de Mayo de 2012.

Las opiniones expresadas por los autores no necesariamente reflejan la postura del editor. necesariamente reflejan la postura del editor. total o parcial de los contenidos e imágenes de la publicación sin previa autorización de la ALCONPAT Internacional A.C.

\section{RESUMO}

O "Palacio de La Luz" é um edifício projetado pelo arquiteto Fresnedo Siri e que foi inaugurado em 1948, em Montevideu, Uruguai. Após mais de 6 décadas em serviço, esta estrutura necessitou de uma intervenção corretiva por conta de fissuras e problemas de infiltração de água pelas fachadas, que exigiram uma inspeção e diagnóstico para obter-se subsídios adequados para a correta elaboração do projeto de reabilitação. Este trabalho de inspeção e diagnóstico foi realizado em duas etapas da sua vida útil, sendo a primeira em outubro de 2004 e a segunda em janeiro de 2009. O objetivo deste trabalho é apresentar uma comparação de resultados obtidos nas duas inspeções, possibilitando avaliar a evolução dos fenômenos de degradação ocorrida durante esses 5 anos de intervalo. As conclusões deste trabalho são que os pilares estruturais não estão comprometidos, os pilares decorativos necessitam de recuperação imediata e a velocidade de carbonatação do concreto do Palacio de La Luz sofreu uma aceleração nos últimos anos.

Palavra-Chave: inspeção; diagnóstico; concreto armado; corrosão.

\section{ABSTRACT}

The "Palacio de La Luz" is a building designed by architect Fresnedo Siri and was inaugurated in 1948 in Montevideo, Uruguay. After more than six decades in service, this structure required a corrective action due to cracks and water infiltration problems in the facades, which required an inspection and diagnosis to obtain adequate subsidies for the correct preparation of the rehabilitation project. This work of inspection and diagnosis was made in two stages of its service life, the first being in October 2004 and the second in January 2009. The aim of this paper is to present a comparison of results obtained in the two inspections, allowing to evaluate the evolution of the phenomena of degradation that occurred during those five years apart. The conclusions are that the structural columns are not compromised, decorative pillars need immediate recovery and the rate of carbonation of the concrete of the Palacio de La Luz has accelerated in recent years.

Key words: inspection; diagnosis; reinforced concrete; corrosion.

Autor de contacto: Marcelo H. F. Medeiros (medeiros.ufpr@gmail.com) 
Revista ALCONPAT, Volumen 2, Número 2, Mayo - Agosto 2012, Páginas 89 - 103

\section{INTRODUÇÃO}

O trabalho de inspeção, diagnóstico, prognóstico e projeto de recuperação de estruturas de concreto armado é algo fascinante para o profissional que gosta de pesquisa aliada a prática. Nesta área profissional é inerente a conciliação entre levantamento de teorias, investigação e comprovação ou não das mesmas, ensaios in loco e em laboratório, interpretação de resultados, estudo e aplicação de materiais e técnicas de recuperação (inovadoras ou já consagradas), além do domínio dos últimos avanços quanto ao prognóstico dos mecanismos de deterioração da estrutura com o intuito de chegar a uma estimativa de vida útil, tanto para o caso de a estrutura sofrer ou não sofrer intervenção.

Faz parte de um bom trabalho de inspeção e diagnóstico de estruturas a sua contextualização histórica, que consiste em ressaltar aspectos arquitetônicos do objeto inspecionado assim como a importância do arquiteto autor do projeto, se este for algum profissional renomado, além do gênero arquitetônico a que a obra pertence. Outra parte importante de um trabalho de inspeção é a caracterização da edificação e das condições de exposição a que a edificação se encontra inserida no momento do trabalho de inspeção. Estas partes precedem a realização de uma campanha de ensaios de campo que apresentam o foco de identificar as causas e efeitos dos mecanismos de degradação atuantes em cada caso.

Os itens que seguem são exatamente a apresentação destas etapas para o caso do trabalho de inspeção no Palacio de La Luz. O trabalho atual tem o objetivo de expor as partes consideradas interessantes deste estudo de caso baseado na inspeção desta mesma estrutura em dois momentos da sua vida útil, sendo a primeira em outubro de 2004 e a segunda em Janeiro de 2009. O foco principal é comparar os resultados obtidos nas duas inspeções, possibilitando avaliar a evolução dos fenômenos de degradação ocorrida durante esses 5 anos de intervalo. Além disso, também é foco deste trabalho mostrar as principais conclusões do trabalho de inspeção realizado. É importante esclarecer que os dados que constam neste artigo, são apenas parte de um relatório de inspeção muito mais abrangente e que a apresentação de todo o trabalho extrapolaria o número de páginas permitido neste meio de comunicação.

\section{HISTÓRICO}

Pode-se considerar fora do foco deste trabalho a importância arquitetônica do Palácio de La Luz (Figura 1) e a relevância do projetista que o idealizou. Porém, estes autores consideram interessante ressaltar a personalidade e representatividade deste arquiteto uruguaio contextualizando o edifício inspecionado com o histórico a seguir.

O arquiteto Román Fresnedo Siri foi uma importante personalidade uruguaia para a formação do quadro arquitetônico latino-americano. Principalmente entre as décadas de 1940 e 1960, com a realização de obras de grande destaque e valor arquitetônico. Sua carreira profissional é marcada pela atuação em seu próprio país, assim como no Brasil e nos Estados Unidos (Weizenmann, 2008).

Em 1948, Fresnedo Siri projetou o "Palacio de la Luz". Foi uma época de muita atividade para este arquiteto, que empregou dois tipos de formas plásticas persistentes. Neste edifício de forma similar aos edifícios para a Organização Pan-americana da Saúde em Washington-EUA (1961) (Figura 2) e em Brasília-Brasil (1971) (Figura 3), foi utilizado o procedimento de nervuras verticais de concreto armado entre as quais foram inseridas as janelas, sem o emprego de alvenarias de vedação de fachadas. 
Revista ALCONPAT, Volumen 2, Número 2, Mayo - Agosto 2012, Páginas 89 - 103

A obra do arquiteto Fresnedo Siri faz parte do modernismo, tendência arquitetônica caracterizada pela oposição a devoção ao ornamento e identificada pelas frases clássicas "menos é mais" e "a forma segue a função".
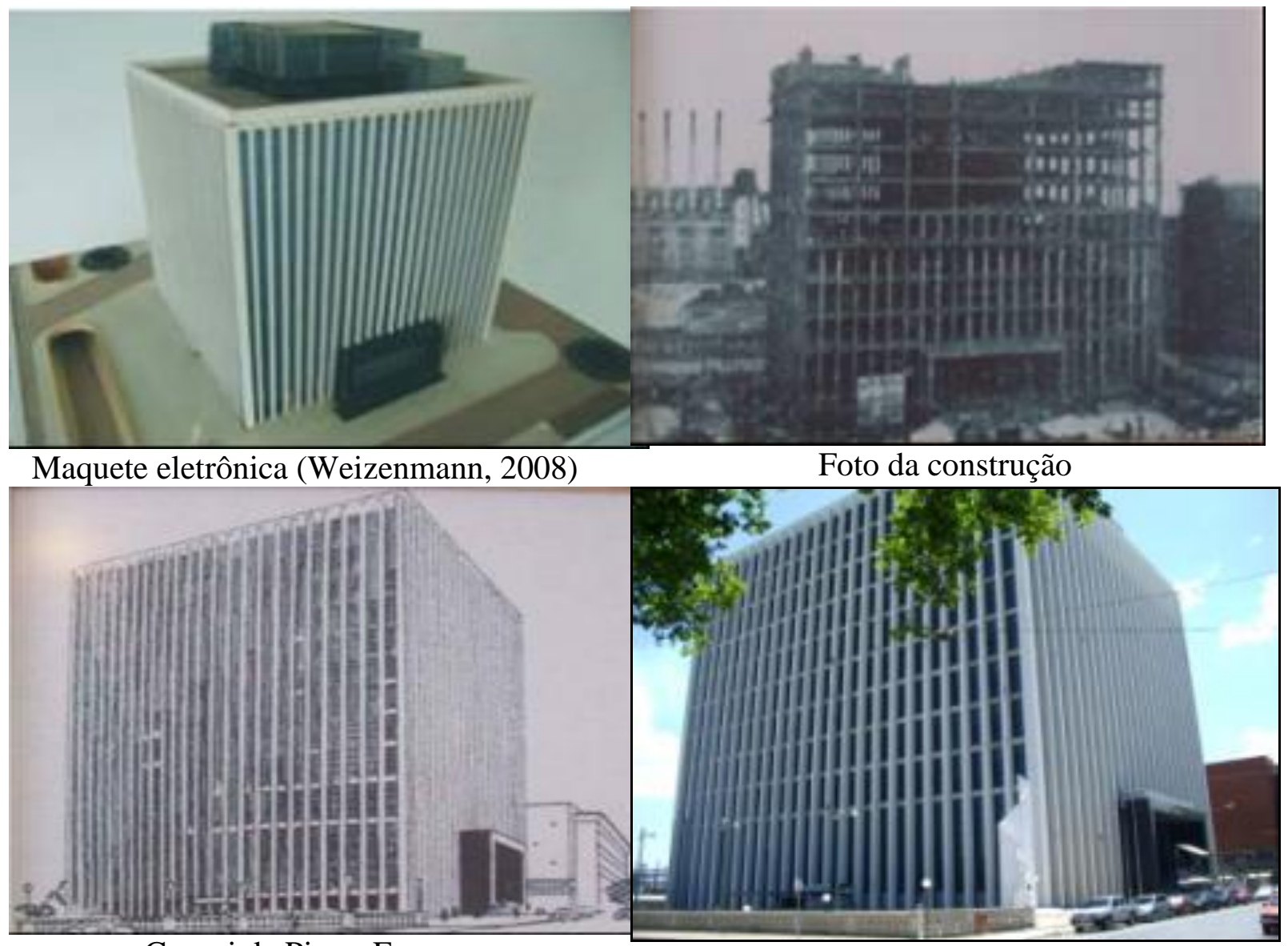

Croqui de Pierre Fossey

Vista de 2009 (Medeiros, 2009)

Figura 1. Palacio de La Luz, Uruguai (1948).

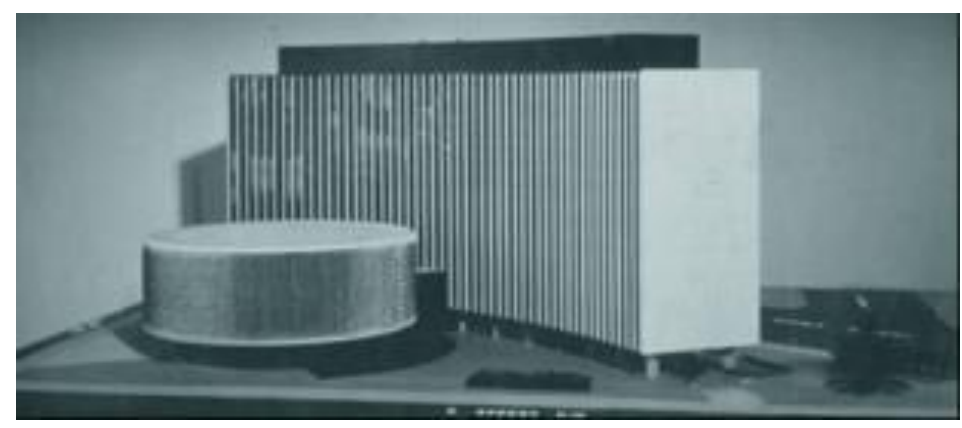

Maquete

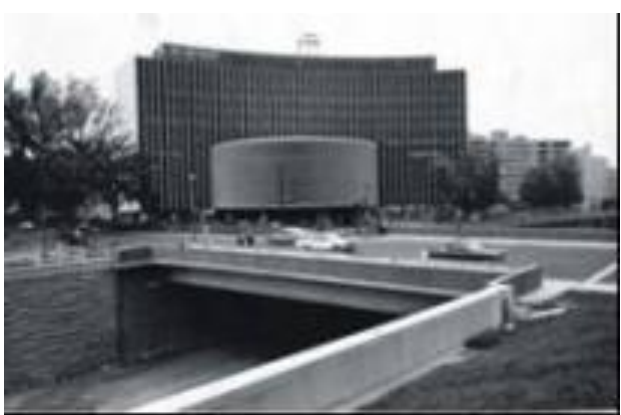

Vista geral

Figura 2. Organização Pan-americana da Saúde, Washington-EUA (1961) (Weizenmann, 2008). 
Revista ALCONPAT, Volumen 2, Número 2, Mayo - Agosto 2012, Páginas 89 - 103

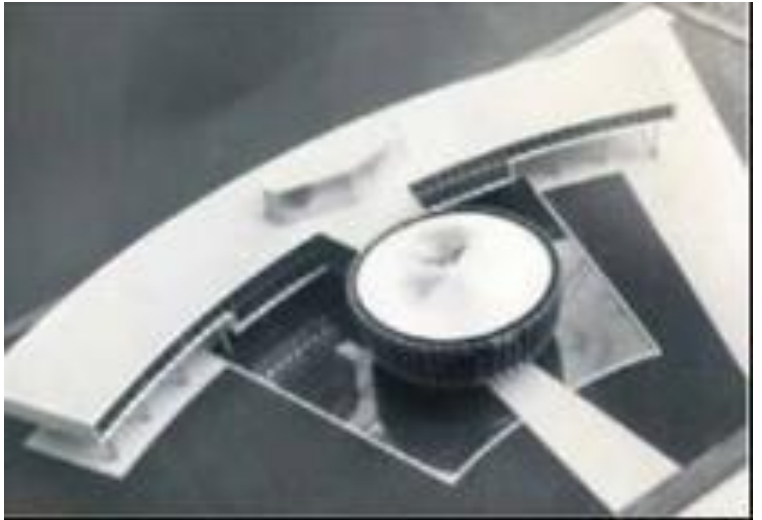

Maquete - vista 1

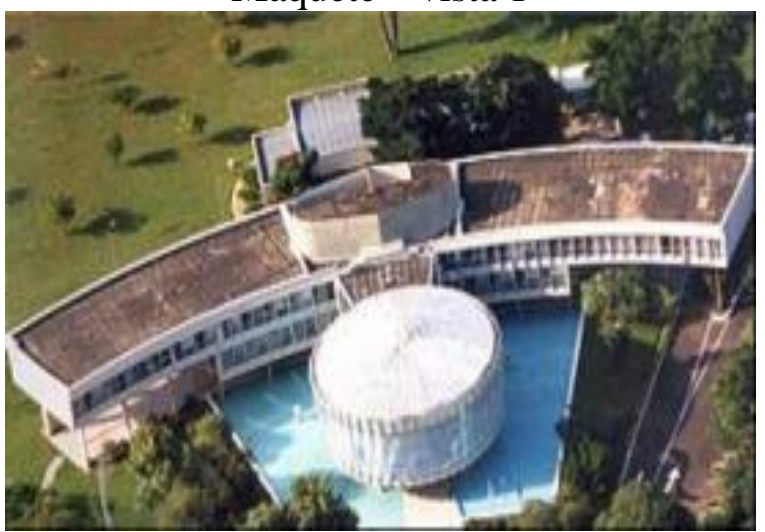

Vista aérea

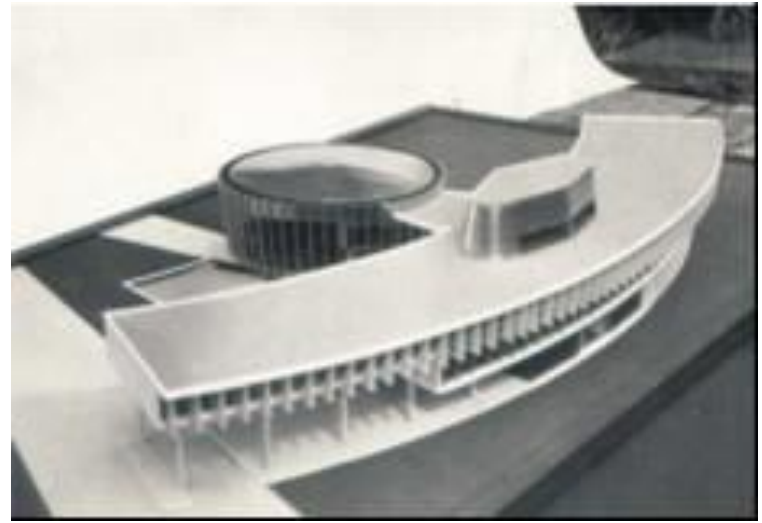

Maquete- vista 2

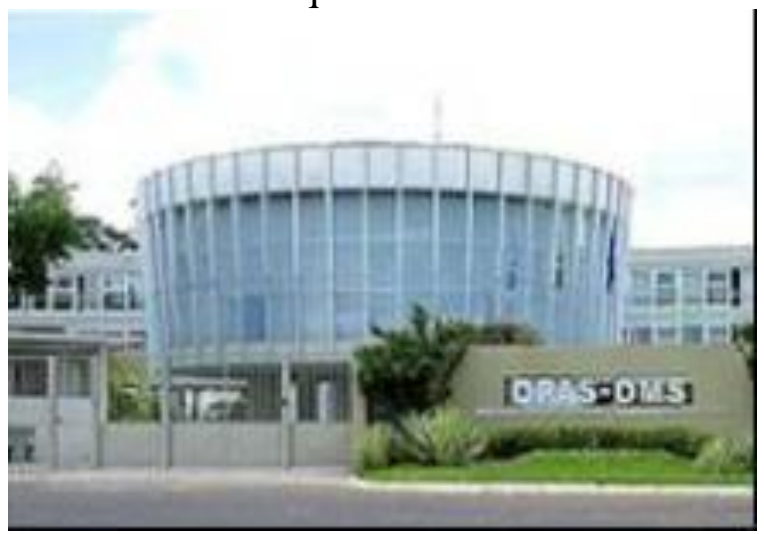

Vista do acesso principal

Figura 3. Organização Pan-americana da Saúde, Brasília-Brasil (1971) (Weizenmann, 2008).

\section{DESCRIÇÃO DA EDIFICAÇÃO E MEIO ONDE ESTÁ INSERIDA}

O Palacio de La Luz apresenta uma forma retangular de 52,2m x 54,2m, gerando uma área edificada de $2.829 \mathrm{~m}^{2}$ por pavimento. Com $47 \mathrm{~m}$ de altura e 11 pavimentos, o Palacio de La Luz apresenta área total de cerca de $31.000 \mathrm{~m}^{2}$. A estrutura é definida por uma malha de pilares marcando a fachada do edifício de modo que apresenta 24 pilares em duas de suas fachadas (Fachada posterior sobre calle Mendoza e Fachada principal sobre calle Paraguay) e 25 pilares nas outras duas fachadas laterais (sobre calle Caraballo e sobre calle Aguilar).

Os pilares de esquina são estruturais e começando das esquinas se dá um ritmo de dois pilares não estruturais, decorativos e ôcos para um estrutural e maciço nas quatro fachadas salvo no tramo central da fachada principal e sua oposta paralela onde entre os pilares estruturais há quatro pilares não estruturais (ôcos e decorativos), conforme ilustra a Figura 4.

O edifício está localizado num centro urbano e próximo o suficiente da costa, sendo passível de receber brisa do Rio de la Plata que nessa região tem água salobra, ou seja, está submetido a um ambiente de agressividade media a forte, classe II a III, segundo a NBR 6118 (NBR 6118, 2004). Por outro lado, os problemas apresentados atualmente não podem ser considerados como de envelhecimento precoce e sim como resultantes de um processo de envelhecimento natural e esperado dessa estrutura sujeita a essa atmosfera em serviço permanente durante quase 6 décadas. 

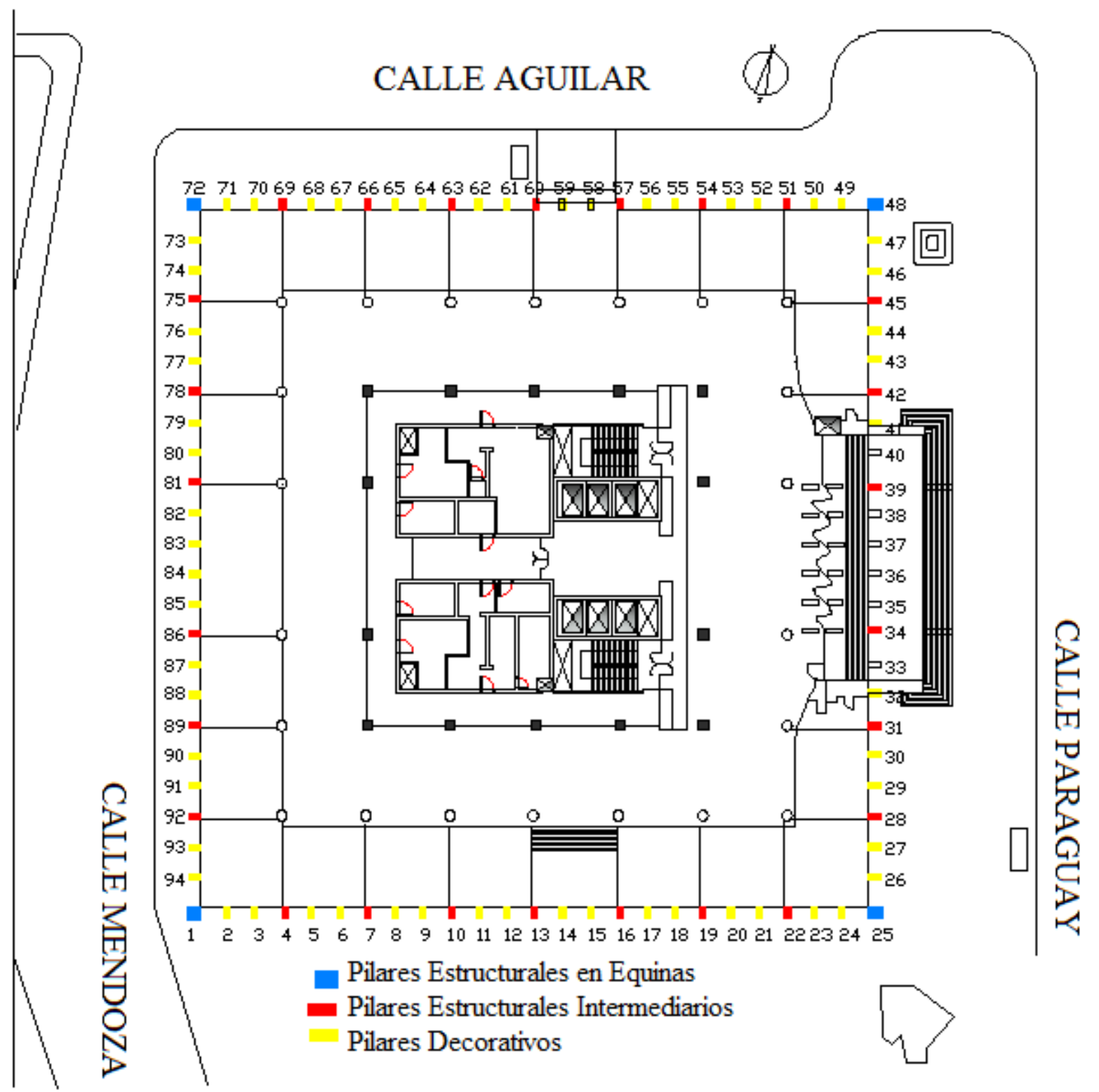

Figura 4. Disposição geométrica dos pilares de concreto na fachada do "Palacio de la Luz".

\section{METODOLOGIA APLICADA}

A inspeção foi conduzida conforme metodologia consagrada nacional (Brasil) e internacionalmente para inspeção de estruturas de concreto. As etapas de trabalho, os ensaios realizados, os dados levantados e os critérios empregados procuram seguir também os cuidados e procedimentos de normas e publicações nacionais e internacionais (Rincón, 1998; Bellmunt, 2000; Helene, 2007; ACI 222R, 2001) empregando-se as recomendações mais relevantes de cada uma. As etapas básicas de trabalho estão apresentadas na Figura 5. 


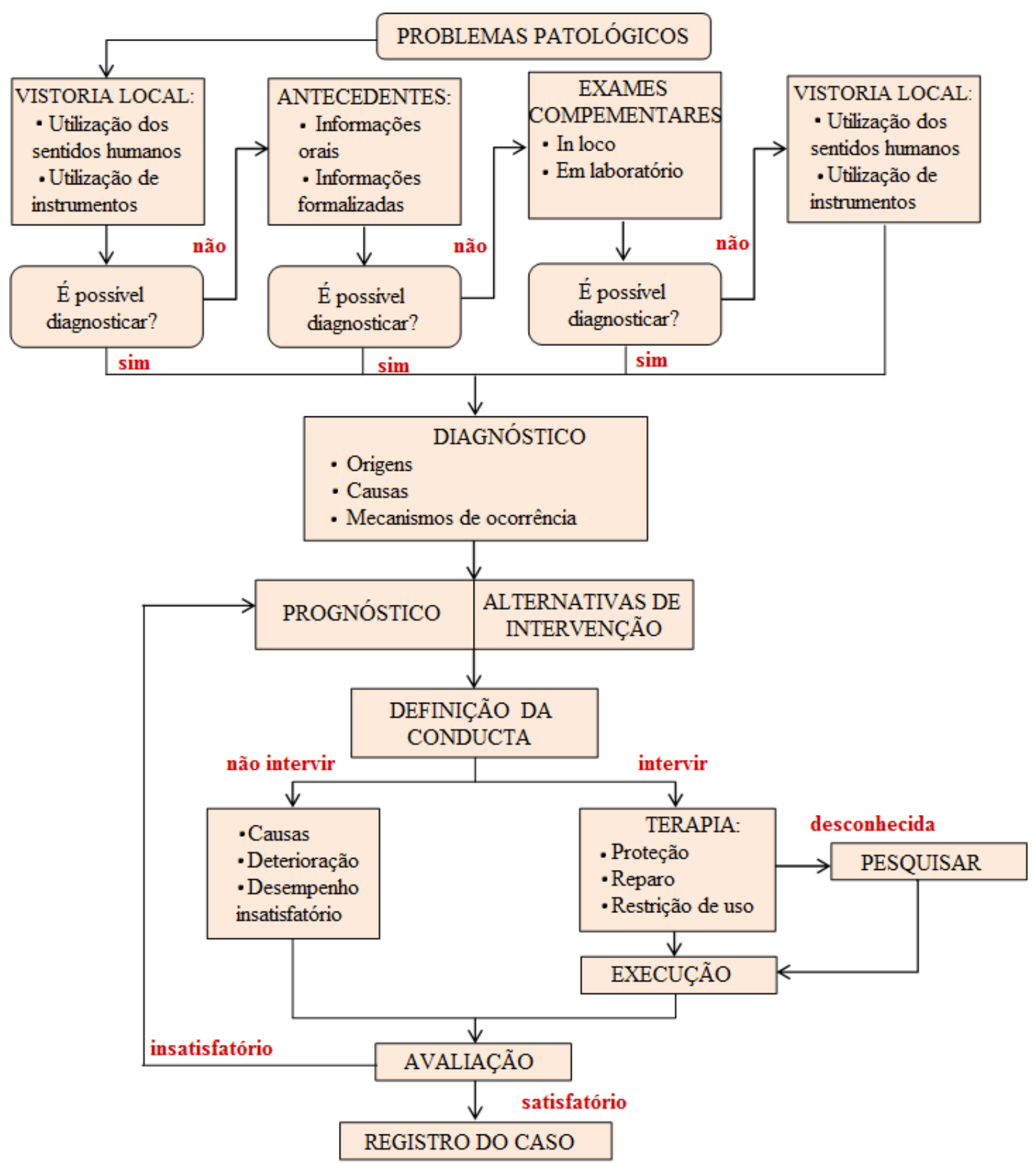

Figura 5. Metodologia geral de inspeção, diagnóstico e prognóstico de manifestações patológicas em obras de construção civil.

A partir da Figura 5, é possível identificar as seguintes etapas principais em um estudo de inspeção e diagnóstico de estruturas:

- Inspeção preliminar: exame visual, levantamento de antecedentes, ensaios expeditos iniciais, definição de teorias para fundamentar o diagnóstico, seleção das informações necessárias a serem levantadas por ensaios, planejamento de trabalho, seleção de áreas de estudo, registro fotográfico de anomalias;

- Inspeção detalhada: realização de ensaios "in loco", retirada de amostras, realização de ensaios em laboratório; 
- Diagnóstico: análise dos resultados dos ensaios e avaliação conjunta das informações disponíveis.

\subsection{Quanto à carbonatação}

A carbonatação é um fenômeno natural que ocorre no concreto e sua velocidade depende de inúmeros fatores, desde aspectos ligados ao concreto como porosidade e reserva alcalina, a aspectos relacionados ao clima como umidade relativa do ar, temperatura, teor de $\mathrm{CO}_{2}$ no ambiente e incidência de ciclos de umedecimento e secagem.

$O$ fato é que quando a frente de carbonatação chega às armaduras ela sai do seu estado de proteção de origem e passa a ter as condições termodinâmicas para o desenvolvimento da corrosão de armaduras que resulta no surgimento de inúmeras manifestações patológicas na estrutura.

Neste trabalho foi utilizado um método semi destrutivo de determinação da profundidade de carbonatação onde normalmente são empregados indicadores químicos, do tipo fenolftaleína (pH de viragem entre 8,3 e 9,3). As determinações foram feitas segundo o método CPC-18 da RILEM (TC -CPC18, 1988) -“Measurement of Hardened Concrete Carbonatation Depth" e a medida da profundidade de carbonatação foi realizada em superfície recém-fraturada do concreto. A Figura 6 ilustra a realização desse ensaio.

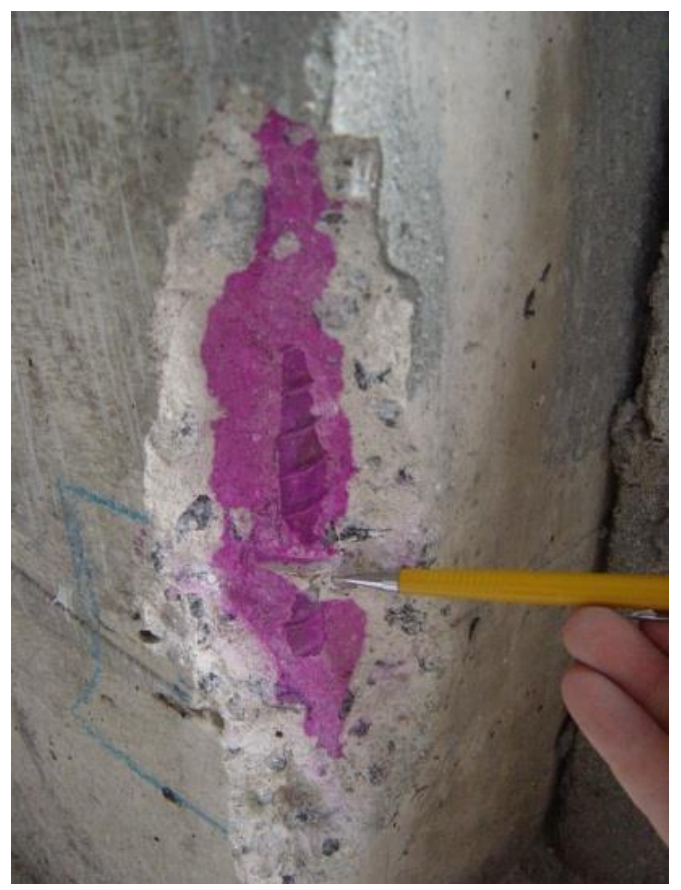

Figura 6. Ensaio de profundidade de carbonatação em pilares de concreto armado.

\subsection{Quanto ao potencial de corrosão (Ecorr)}

A determinação do potencial de corrosão consiste em colher informações relativas ao estado termodinâmico da corrosão, ou seja, a indicação do estado passivo ou de corrosão das armaduras embutidas nos elementos estruturais inspecionados.

Este tipo de medida foi conduzido mediante a aplicação de um método eletroquímico não destrutivo que segue o procedimento da ASTM C 876 (ASTM C 876,1999). O equipamento utilizado consiste em um eletrodo de referência de $\mathrm{Cu} / \mathrm{CuSO}$ ligado a um voltímetro de elevada impedância de entrada, conforme ilustrado na Figura 7. A Tabela 1 expressa os critérios 
Revista ALCONPAT, Volumen 2, Número 2, Mayo - Agosto 2012, Páginas 89 - 103

frequentemente utilizados para a avaliação termodinâmica da corrosão através da medida do potencial de corrosão.

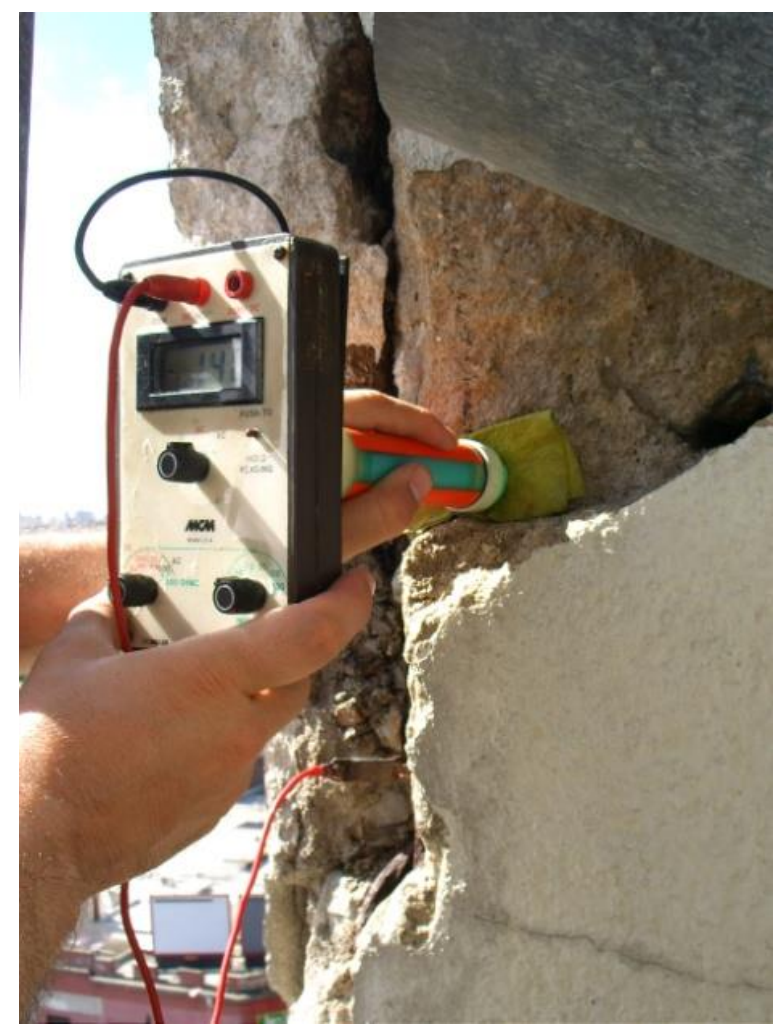

Figura 7. Ensaio de potencial de corrosão utilizando eletrodo de $\mathrm{Cu} / \mathrm{CuSO} 4$ (ASTM C 876, 1999).

Tabela 1. Critério de avaliação da corrosão através do potencial de corrosão.

\begin{tabular}{|c|c|}
\hline $\begin{array}{c}\text { Potencial de corrosão } \\
\text { (eletrodo de Cu/CuSO} \text { ) }\end{array}$ & $\begin{array}{c}\text { Probabilidade de corrosão } \\
\text { (ASTM C 876) }\end{array}$ \\
\hline$<-350 \mathrm{mV}$ & $95 \%$ \\
\hline entre $-350 \mathrm{mV}$ e $-200 \mathrm{mV}$ & $50 \%$ \\
\hline$>-200 \mathrm{mV}$ & $5 \%$ \\
\hline
\end{tabular}

\subsection{Quanto à velocidade de corrosão (icorr)}

A velocidade de corrosão é o parâmetro que caracteriza a cinética do processo de corrosão, define a taxa de deterioração das armaduras e, portanto, da própria estrutura afetada pela corrosão.

Um dos métodos mais empregados para a medida da velocidade de corrosão é a "resistência de polarização" (Rp) que é um ensaio aplicado regularmente a partir da década de 90 por Andrade e González (Andarade, 1988), que adaptaram e desenvolveram as técnicas originalmente empregadas no fim da década de 50 por Kaesche e Baumel \& Engell, para armaduras embebidas em argamassa e concreto.

Esse ensaio é também conhecido por ensaio de "polarização linear" e os critérios de avaliação da corrosão segundo esta técnica encontram-se na Tabela 2.

Para as leituras de velocidade de corrosão foi utilizado um equipamento denominado comercialmente como Gecor, que é um aparelho de medida da velocidade de corrosão in loco, conforme ilustrado na Figura 8. 
Revista ALCONPAT, Volumen 2, Número 2, Mayo - Agosto 2012, Páginas 89 - 103

Tabela 2. Critérios de avaliação da corrosão segundo a medida da velocidade de corrosão.

\begin{tabular}{|c|c|}
\hline Velocidade de corrosão & Critério de avaliação da corrosão \\
\hline$<0,1 \mu \mathrm{A} / \mathrm{cm}^{2}$ & corrosão desprezível \\
\hline entre 0,1 a $0,2 \mu \mathrm{A} / \mathrm{cm}^{2}$ & corrosão baixa \\
\hline entre 0,2 a $0,5 \mu \mathrm{A} / \mathrm{cm}^{2}$ & corrosão moderada \\
\hline entre 0,5 a $1,0 \mu \mathrm{A} / \mathrm{cm}^{2}$ & corrosão alta \\
\hline entre 1,0 a $10,0 \mu \mathrm{A} / \mathrm{cm}^{2}$ & corrosão muito alta \\
\hline
\end{tabular}

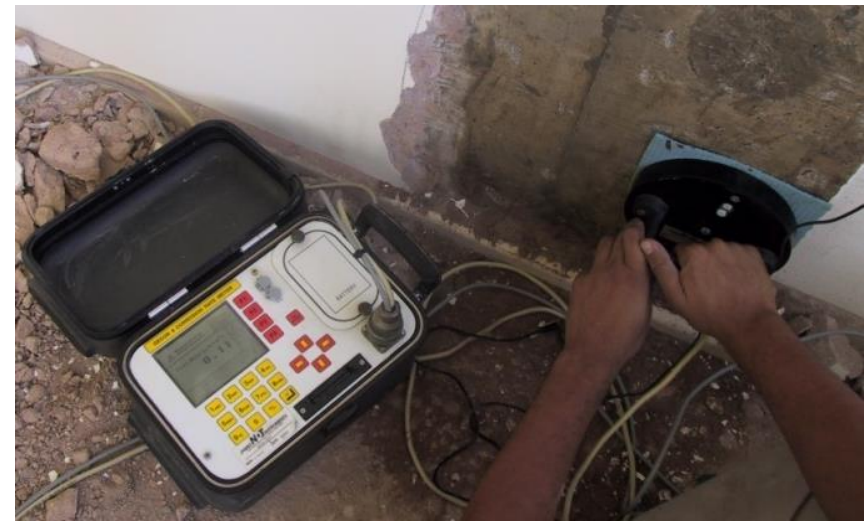

Figura 8. Leitura da velocidade de corrosão com o GECOR.

\subsection{Perda de secção}

A determinação da perda de seção das armaduras é um dos pontos importantes em um trabalho de inspeção desta natureza pela necessidade da estimativa da perda de capacidade resistente dos elementos estruturais da edificação.

Ela representa o quanto de massa as barras de aço já perderam devido ao desenvolvimento da corrosão de armaduras. Esse ensaio foi conduzido por prospecção, a partir da limpeza mecânica do aço e medida do seu diâmetro com paquímetro digital em trechos expostos das armaduras dos pilares que fazem parte da amostragem realizada. A Figura 9 ilustra o resultado da limpeza para viabilizar a leitura.

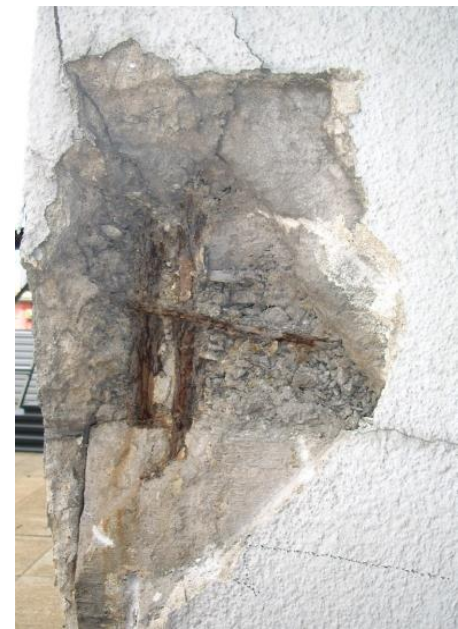

(A)

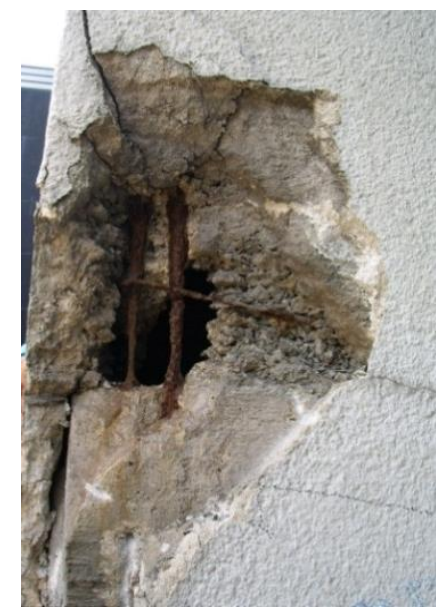

(B)

Figura 9. Detalhe da limpeza para medir perda de seção transversal: (A) antes da limpeza; (B) após a limpeza. 
Revista ALCONPAT, Volumen 2, Número 2, Mayo - Agosto 2012, Páginas 89 - 103

\section{RESULTADOS}

Nesta seção não se pretendeu apresentar todos os resultados obtidos no trabalho de inspeção realizado, pois isso resultaria em um trabalho mais extenso do que o que se considera adequado para um artigo técnico. Deste modo, foram escolhidos alguns aspectos a serem discutidos a seguir:

\subsection{Carbonatação}

As Figuras 10 e 11 apresentam os resultados de profundidade de carbonatação obtidos na inspeção realizada em 2004 e em 2009, cujos dados se referem aos mesmos pontos amostrados em cada inspeção realizada. Com esta conduta foi possível montar uma comparação do estado dos pilares estruturais e dos decorativos nos dois momentos de inspeção. Comparando as Figuras 10 e 11 é fácil notar que os valores de profundidade de carbonatação são maiores nos pilares decorativos do que nos estruturais, indicando que a qualidade do concreto é diferente em ambos os casos.

Os dados das Figuras 10 e 11 indicam que houve uma evolução considerável da carbonatação no intervalo de pouco mais de 4 anos entre os dois momentos de inspeção. Isto de certa forma contradiz o que se conhece da literatura, que consiste na tendência de redução da velocidade de carbonatação com o passar do tempo, relacionada com o fato de que o processo de carbonatação tende a reduzir a porosidade do concreto carbonatado, ou seja, a camada carbonatada de uma peça de concreto tende a dificultar o acesso de mais dióxido de carbono as camadas não carbonatadas mais internas. Isso leva a redução da velocidade de carbonatação ao longo do tempo, como preconizado pelo modelo clássico $x_{\mathrm{CO}_{2}}=k_{\mathrm{CO}_{2}} \cdot \sqrt{t}$, (TUUTTI, 1982). O efeito da redução da porosidade do concreto causado pelo processo de carbonatação foi confirmada nos ensaios de Medeiros \& Helene (2001) (Medeiros, 2001).

Uma possível explicação para a contradição citada é o crescimento da cidade de Montevidéu que resulta em maior poluição do ar e consequentemente maior quantidade de $\mathrm{CO}_{2}$ disponível para a reação de carbonatação. Este efeito é contrário ao efeito do processo de desaceleração da carbonatação pela densificação das camadas carbonatadas. O efeito da maior concentração de dióxido de carbono na agressividade do ambiente é reconhecida pelos códigos mundiais de modo que as especificações para concretos atuais são mais conservadoras para os casos em que existe tendência de maior concentração de $\mathrm{CO}_{2}$, como a clássica divisão entre ambiente rural e ambiente urbano.

O fato é que a profundidade de carbonatação encontrada em 2009 é, na grande maioria dos casos, mais do que o dobro da encontrada na inspeção de 2004 indicando a elevação da velocidade de avanço da frente de carbonatação do concreto da estrutura. Esse é um dos fatos que evidencia a importância da tomada de decisão no sentido de intervir nesta estrutura o quanto antes para desacelerar a agressão provocada pelo dióxido de carbono da atmosfera local, agravado pela presença de chuva ácida e outros contaminantes atmosféricos.

É claro que a influência de erros de leituras ou mudanças de procedimentos entre as inspeções de 2004 e 2009 não pode ser descartada, porém, estes autores não acham provável que esta seja a explicação para as consideráveis diferenças entre as leituras de 2004 e 2009 uma vez que ambas foram conduzidas pela mesma equipe de campo.

Apesar de tudo, é importante reconhecer que os valores de profundidade de carbonatação encontrados são muito baixos considerando que se trata de uma estrutura com mais de 50 anos em serviço. As regiões onde existiam armaduras em estado de corrosão ativa coincidiam com regiões de concreto mal adensado formando ninhos de concretagem, estando este concreto 
Revista ALCONPAT, Volumen 2, Número 2, Mayo - Agosto 2012, Páginas 89 - 103

carbonatado. Ou seja, falhas relacionadas com deficiências localizadas de execução dos pilares de concreto armado.

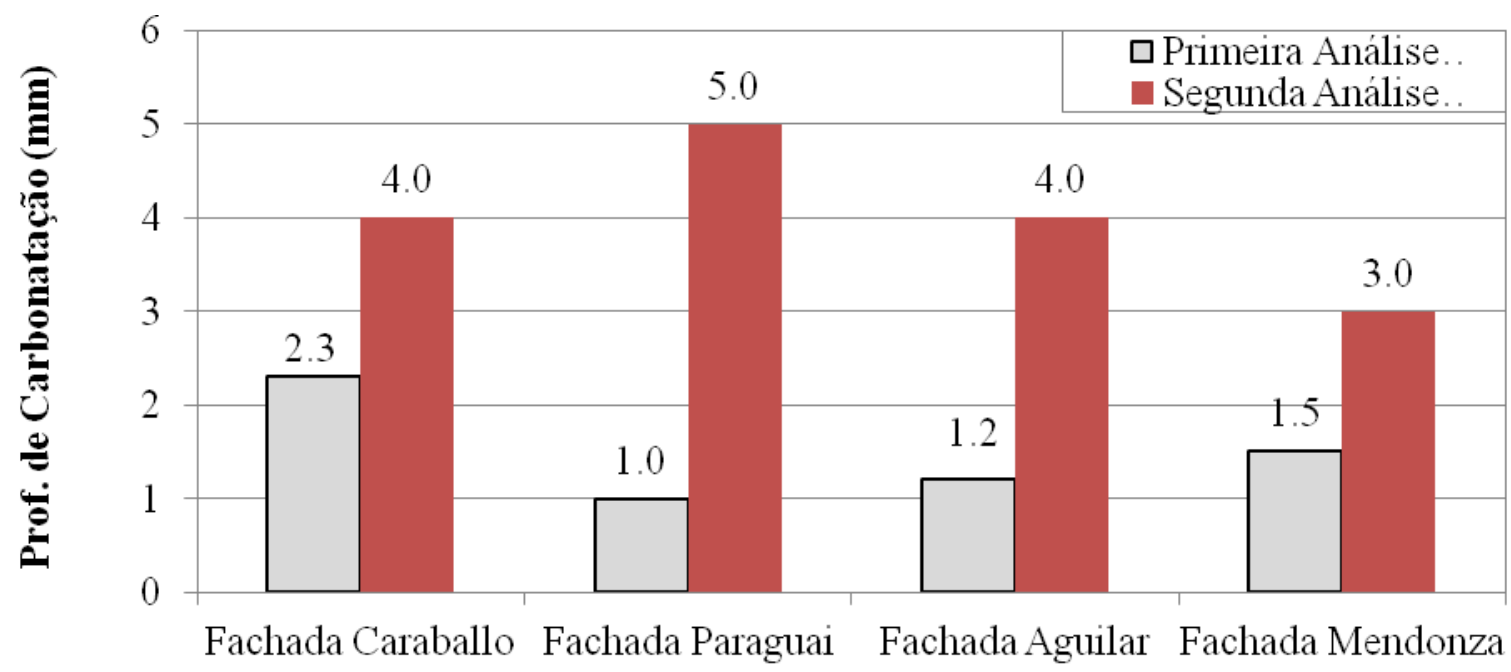

Pilares Estruturais (PE)

Figura 10. Comparação de resultados de carbonatação da inspeção de 2004 com a de 2009 para os pilares estruturais (PE).

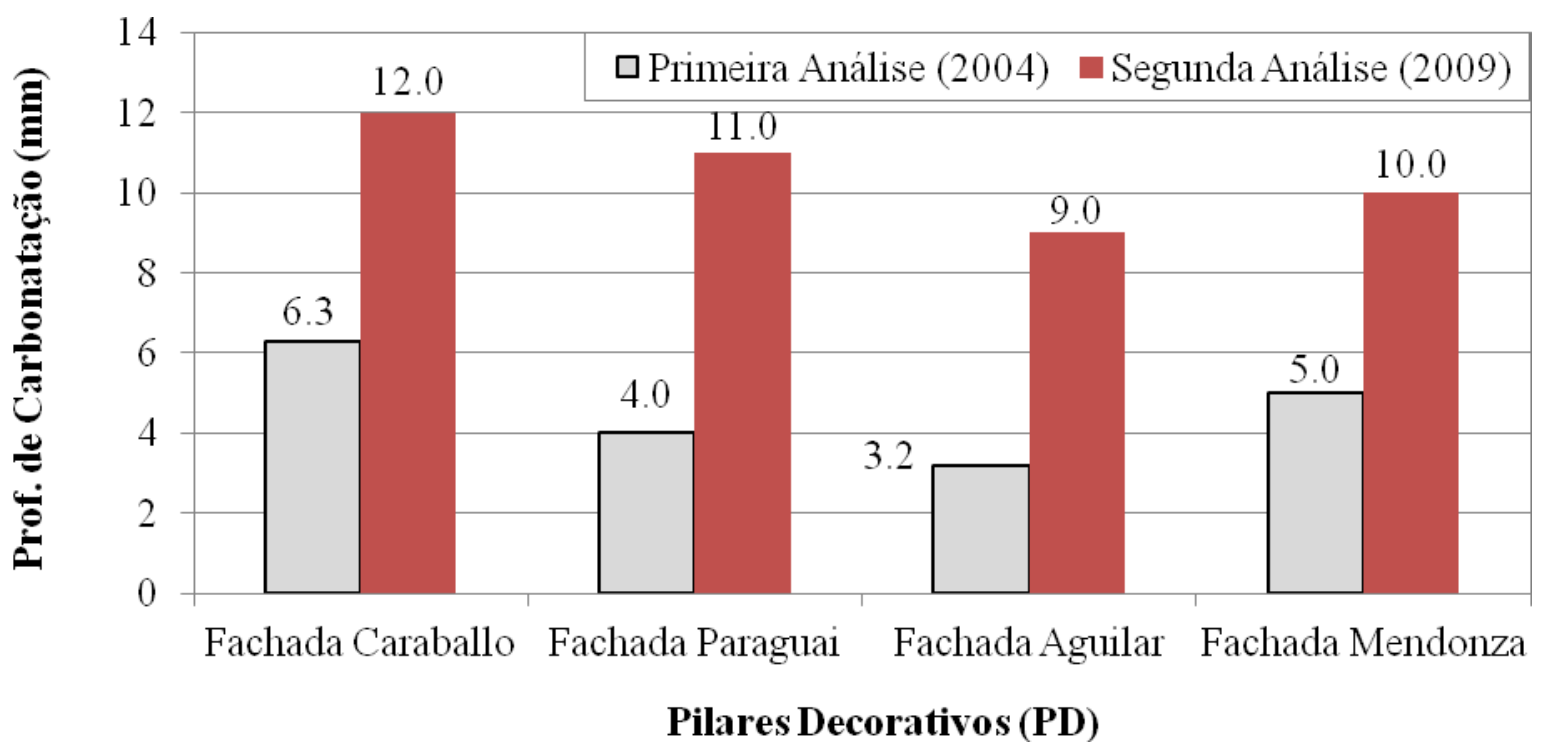

Figura 11. Comparação de resultados de carbonatação da inspeção de 2004 com a de 2009 para os pilares decorativos (PD).

\subsection{Potencial de corrosão}

Os resultados apresentados nas Figuras 12 e 13 indicam com 95\% de confiança que as armaduras dos pilares decorativos se encontram em estado ativo de corrosão, enquanto que nos pilares estruturais a probabilidade de corrosão ativa é de apenas $5 \%$.

Esta é uma constatação importante que indica que os pilares de sustentação da estrutura (estruturais) ainda estão em boas condições em termos de durabilidade e os locais em estado de corrosão ativa estão isolados nos elementos não estruturais. 
Revista ALCONPAT, Volumen 2, Número 2, Mayo - Agosto 2012, Páginas 89 - 103

Além disso, as Figuras 12 e 13 foram idealizadas para estudar a mudança do estado termodinâmico de corrosão nas duas inspeções. Contudo, os resultados indicam que não houve mudança significativa na condição de 2004 para 2009, ou seja, quem era classificado como corrosão passiva continou da mesma forma em 2009.

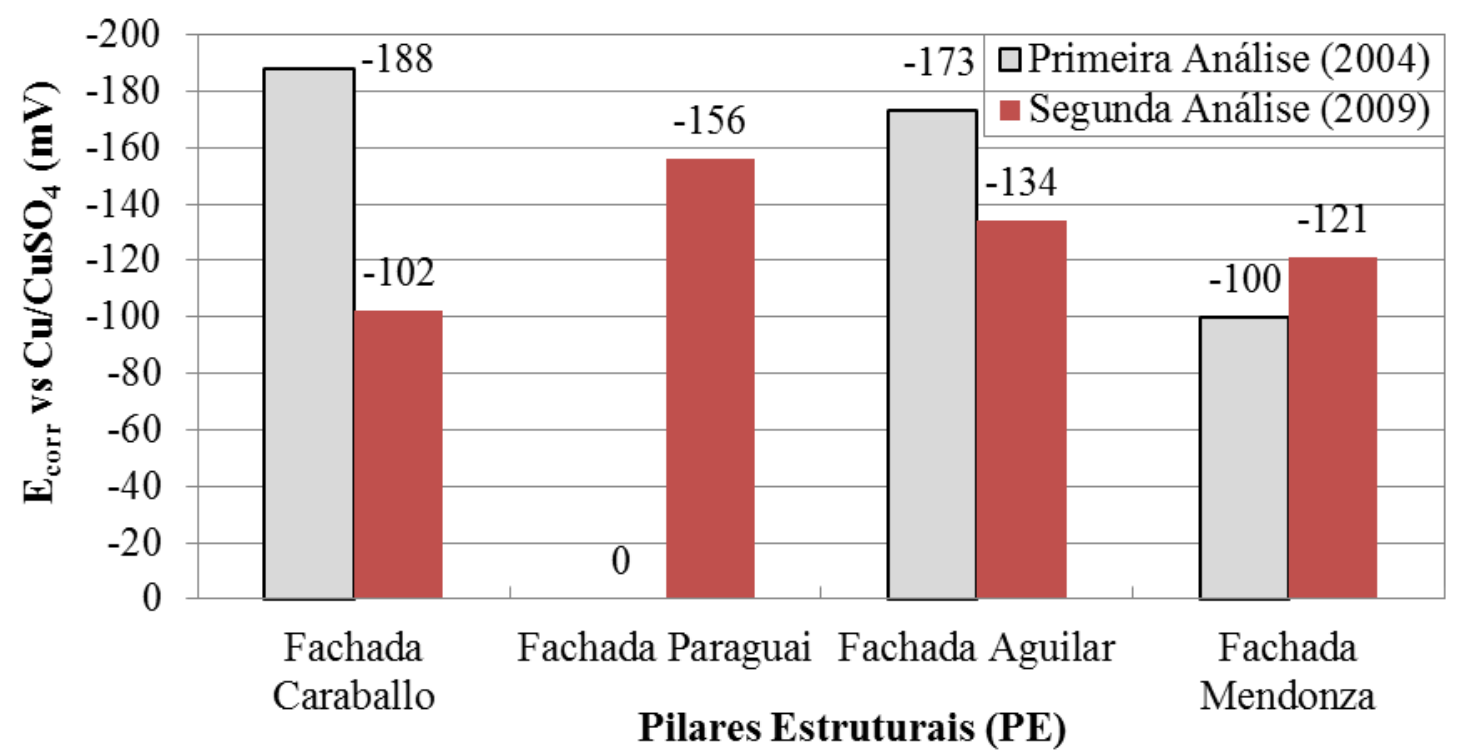

Figura 12. Potencial de corrosão da inspeção de 2004 com a de 2008/2009 para os pilares estruturais (PE).

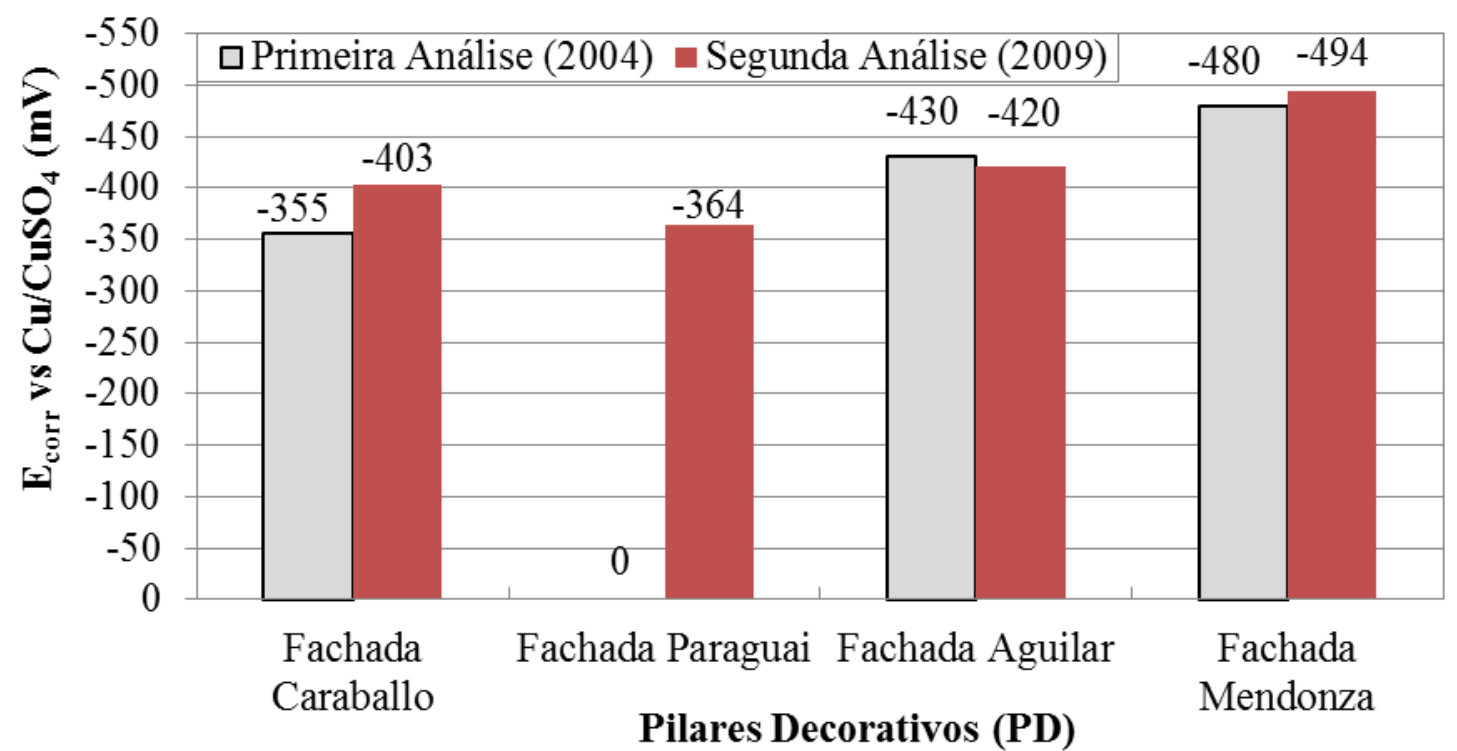

Figura 13. Potencial de corrosão da inspeção de 2004 com a de 2008/2009 para os pilares decorativos (PD).

\subsection{Velocidade de corrosão (icorr)}

A Tabela 3 apresenta os valores de velocidade de corrosão obtidos em um ponto em cada uma das fachadas da edificação inspecionada. De modo similar ao verificado em 2004, segundo os critérios amplamente aceitos pelos especialistas da área, correntes de corrosão acima de 0,1 a 0,2 $\mu \mathrm{A} / \mathrm{cm}^{2}$ são fortes indícios de processo corrosivo ativo e significativo. 
Revista ALCONPAT, Volumen 2, Número 2, Mayo - Agosto 2012, Páginas 89 - 103

Em conformidade com os dados de potencial de corrosão, os resultados indicam que os pilares estruturais apresentam-se com baixíssimos valores de velocidade de corrosão e os pilares decorativos apresentam valores acima de $0,2 \mu \mathrm{A} / \mathrm{cm}^{2}$, que indicam corrosão ativa.

Tabela 3. Velocidade de corrosão determinado com Gecor.

\begin{tabular}{|c|c|c|}
\hline Local & PE13 & PD12 \\
\hline \multirow{2}{*}{ Fachada Caraballo } & icorr $\left(\mu \mathrm{A} / \mathrm{cm}^{2}\right)$ & icorr $\left(\mu \mathrm{A} / \mathrm{cm}^{2}\right)$ \\
\cline { 2 - 3 } Local & 0,04 & 0,39 \\
\hline \multirow{2}{*}{ Fachada Paraguai } & PE31 & PD30 \\
\cline { 2 - 3 } Local & icorr $\left(\mu \mathrm{A} / \mathrm{cm}^{2}\right)$ & icorr $\left(\mu \mathrm{A} / \mathrm{cm}^{2}\right)$ \\
\hline \multirow{2}{*}{ Fachada Aguilar } & 0,03 & 0,46 \\
\cline { 2 - 3 } & PE66 & PD52; PD53 e PD65 \\
\hline \multirow{2}{*}{ Local } & icorr $\left(\mu \mathrm{A} / \mathrm{cm}^{2}\right)$ & 0,60 \\
\hline \multirow{2}{*}{ Fachada Mendonza } & 0,05 & PD88 \\
\cline { 2 - 3 } & PE89 & icorr $\left(\mu \mathrm{A} / \mathrm{cm}^{2}\right)$ \\
\hline
\end{tabular}

\subsection{Perda de seção transversal das armaduras}

A Tabela 4 apresenta os resultados de perda de seção determinados a partir do procedimento descrito anteriormente. É fácil constatar que existem localidades com perda de seção transversal da barra superiores a 10\%, chegando em alguns casos a perder $34 \%$ da secção original de aço. Perdas dessa ordem tornam indispensável, conveniente e seguro, a reposição da secção de aço original constante do projeto estrutural dessa estrutura.

Tabela 4. Perda de seção transversal das armaduras em pontos amostrados.

\begin{tabular}{|c|c|c|c|c|c|c|c|}
\hline Fachada & Pilar & Pavimento & $\begin{array}{c}\varnothing \\
\text { nominal } \\
(\mathrm{mm})\end{array}$ & $\begin{array}{c}\text { Seção } \\
\text { nominal } \\
\left(\mathbf{m m}^{2}\right)\end{array}$ & $\begin{array}{c}\varnothing \\
\text { medido } \\
(\mathrm{mm})\end{array}$ & $\begin{array}{c}\text { Seção } \\
\text { medida } \\
\left(\mathbf{m m}^{2}\right)\end{array}$ & $\begin{array}{c}\text { Perda de } \\
\text { seção }(\%)\end{array}$ \\
\hline Caraballo & PD 03 & térreo & 16,0 & 201 & 15,5 & 189 & 6 \\
\hline Caraballo & PD 14 & entre $5^{\circ}$ e $6^{\circ}$ & 12,5 & 123 & 11,5 & 104 & 15 \\
\hline Paraguay & PD 47 & térreo & 16,0 & 201 & 15,5 & 189 & 6 \\
\hline Paraguay & PD 30 & entre $5^{\circ}$ e $6^{\circ}$ & 12,5 & 123 & 11,5 & 104 & 15 \\
\hline Aguilar & PD 64 & térreo & 16,0 & 201 & 13,5 & 143 & 29 \\
\hline Mendonza & PD 80 & térreo & 16,0 & 201 & 13,0 & 133 & 34 \\
\hline Mendonza & PD 76 & entre $3^{\circ}$ e $4^{\circ}$ & 16,0 & 201 & 14,6 & 167 & 17 \\
\hline Mendonza & PD 88 & entre $7^{\circ}$ e $8^{\circ}$ & 12,5 & 123 & 11,5 & 104 & 15 \\
\hline
\end{tabular}

\section{DISCUSSÃO}

Os resultados deste trabalho mostram indícios de que, em condições reais, nem sempre existe uma redução da velocidade de carbonatação com o passar do tempo de vida útil de uma estrutura de concreto armado. A desaceleração deste processo de degradação ocorre em teoria, porém, o nível de desenvolvimento das cidades tem aumentado consideravelmente ao longo das décadas 
em muitas cidades e a consequiência disso é a elevação dos níveis de concentração de dióxido de carbono no ar.

Em 1948, certamente o nível de desenvolvimento de Montevidéu era muito menor, menor número de carros nas ruas e menor desenvolvimento industrial. Este processo de desenvolvimento está ocorrendo em inúmeras partes do planeta e o exemplo deste estudo é um fator alarmante para os profissionais que tem contato com o concreto armado. Esta é uma das lições deste trabalho. As estruturas de concreto armado que eram adequadas no passado podem não o ser hoje em dia e precisamos refletir e tomar providências quanto a isso.

No Brasil, a NBR 6118 (NBR 6118, 2004) de 2004 já foi um passo neste sentido quando conseguiu começar a tratar o tema durabilidade e usar a divisão em macro-climas (urbano, marinho e rural) na norma de cálculo estrutural, mas só isso não é o bastante, novos avanços são necessários.

Especificamente sobre o caso em questão, é importante destacar que não se considera que o "Palacio de la Luz" apresenta problema estrutural, uma vez que todos os pilares estruturais estão íntegros e sem perda de seção das armaduras acima de $10 \%$.

Porém, pode-se dizer que, apesar do grande problema de corrosão avançada e desplacamentos do cobrimento concentrar-se nos pilares decorativos, é importante ressaltar que é de extrema importância a tomada de decisão imediata, já que este tipo de ocorrência coloca o usuário em risco e afeta a estética do Palacio de La Luz.

Um fator interessante neste serviço de inspeção foi o fato de a contaminação por cloretos ser pequena e a frente de carbonatação não ter atingido as armaduras em inúmeras regiões estudadas. Isto fez os profissionais envolvidos no trabalho questionarem o que teria ocasionado a despassivação das armaduras.

Mas a avaliação cuidadosa da edificação levou a concluir que os locais de incidência de corrosão de armaduras estavam concentrados em regiões de concreto de alta porosidade e com alto nível de carbonatação (ver Figura 14). Isto significa que o mecanismo de despassivação é a carbonatação facilitada por falha de execução (adensamento insuficiente) da estrutura de concreto armado.
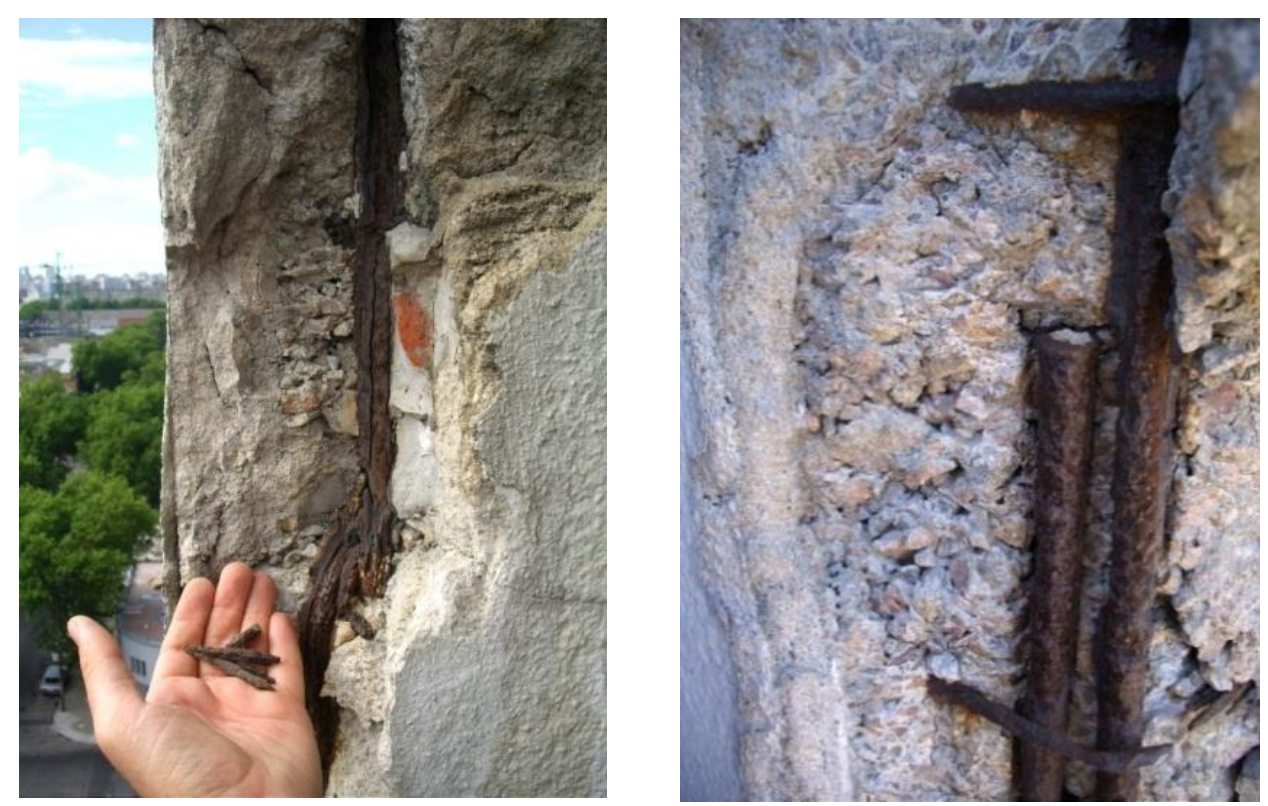

Figura 14. Pilares decorativos com corrosão acentuada em área com concreto de alta porosidade. 
Revista ALCONPAT, Volumen 2, Número 2, Mayo - Agosto 2012, Páginas 89 - 103

\section{CONCLUSÕES}

As conclusões deste trabalho podem ser enumeradas a seguir:

- Os pilares estruturais do Palacio de La Luz não estão comprometidos pelo processo de corrosão de armaduras;

- Os pilares decorativos do Palacio de La Luz apresentaram incidência de corrosão acentuada com elevados níveis de velocidade de corrosão e de perda de seção;

- O trabalho de inspeção neste caso mostra indícios de que o processo de carbonatação do concreto do Palacio de La Luz está se acelerando e isso indica que a tomada de decisão para recuperação deste prédio deve ser imediata;

- A metodologia de inspeção empregada analisando conjuntamente os resultados e profundidade de carbonatação, potencial de corrosão, velocidade de corrosão e perda de seção, neste caso, pareceu ser satisfatória para o diagnóstico da edificação.

\section{REFERENCIAS}

ACI 222R (2001), Protection of metals in concrete against corrosion. American Concrete Institute, Farmington Hills, MI, USA.

Andrade C., Gonzalez J. A. (1988), Tendencias Actuales en la Investigación sobre Corrosion de Armaduras, Informes de la Construcción, v. 40, n. 398, p. 7-14.

ASTM C 876 (1999), Standard test method for half-cell potentials of uncoated reinforcing steel in concrete. In: Annual book of ASTM Standards. Philadelphia, USA.

Bellmunt R., Casanovas X., Casanovas M. F., Diaz C., Helene P. R. L., Rosell J., Rosell J. R., Vàzquez E. (2000), Manual de diagnosis e intervención en estruturas de hormigón armado, Barcelona: Collegi d'Aparelladors i Arquitectes Técnics de Barcelona, Espanha.

Helene P., Pereira F. (2007), Rehabilitación y Mantenimiento de Estructuras de Concreto, São Paulo, Brasil.

Medeiros M. H. F., Giordano D. E., Britez C. A., Helene P. (2009) Inspeção e diagnóstico dos pilares e vigas de concreto armado da fachada do edificio "Palacio de la Luz", Parecer Técnico $\mathrm{n}^{\circ}$ 13, São Paulo, Brasil.

Medeiros, M. H. F., Helene, P. (2001) Estudo da carbonatação em concretos e argamassas. Revista Engenharia Ciência \& Tecnologia, Espírito Santo, v. 4, n. 5, p. 3-12.

NBR 6118 (2004), Projeto de estruturas de concreto - Procedimento. Associação Brasileria de Normas Técnicas - ABNT. Rio de Janeiro, Brasil.

Rincón O. T., Carruyo C. A., Helene P., Díaz I. (1998), Manual de inspeccion, evaluacion y diagnostico de corrosion en estruturas de hormigon armado, DURAR: Red Tematica XV. B Durabilidad de la Armadura - Programa Iberoamericano de Ciencia y Tecnología para el desarrollo.

TC -CPC18 (1988), RILEM Measurement of hardened concrete carbonation depth.

TUUTTI, K. (1982), Corrosion of Steel in Concrete.Cement and Concrete Research. n. 504, p. 469.

Weizenmann J. M. S. (2008), A arquitetura de Román Fresnedo Siri (1938-1971), Dissertação de Mestrado, Universidade Federal do Rio Grande do Sul, Porto Alegre, Brasil. 